\title{
Overview of Geriatrics Studies via the 14th EUGMS (European Geriatric Medicine Society) Congress 2018: From Turkey's Point of View
}

\author{
(1) Fatma Özge Kayhan Koçak, (1) Sevnaz Şahin, (1) Selahattin Fehmi Akçiçek \\ Ege University Faculty of Medicine, Department of Internal Medicine, Division of Geriatrics, Izmir, Turkey
}

\begin{abstract}
New developments in the field of health should be organized according to aging and cover older people. For this purpose, the European Geriatric Medicine Society organized a congress titled "Advancing Geriatric Medicine in a Modern World" in this year. Symposium covered a wide variety of topics in geriatric medicine, such as geriatric approaches in common chronic diseases, new evaluation methods and treatments in geriatric syndromes. The aim of this study was to evaluate geriatrics studies in Turkey with a critical perspective in order to keep up with the evolving world. All multidisciplinary studies in Turkey involve collaboration among healthcare professionals only. Participants from different disciplines were not only informed of the latest developments in geriatric medicine; also, they had the opportunity to exchange views in this area through the congress. It is thanks to the congress, that geriatrics has been making efforts to be more inclusive in Turkey.
\end{abstract}

Keywords: Congress report, EUGMS, geriatrics studies

\section{Introduction}

Human life span is prolonged with the new developments in the field of technology and medicine. Consequently, the population is aging in the whole world, especially in Europe. New developments in the field of health should be organized according to aging and cover older people. For this purpose, the European Geriatric Medicine Society (EuGMS) organizes a congress every year since 2005 to give geriatric viewpoint to all clinicians interested in advanced age patients. "Advancing Geriatric Medicine in a Modern World" was the name of 14th congress in October 2018.

The 14th EuGMS Congress was held from the 10th to the 12th of October 2018 in Berlin, Germany, and had gathered more than 1800 participants from 65 countries. The $14^{\text {th }}$ congress was opened with a concert of Johann Sebastian Bach music, after a great speech on the creativity of Johann Sebastian Bach on October 10, 2018.
The aim of this year's congress was to focus on developments that were significantly affected by technological and pharmaceutical innovations, and to present new concepts that have evolved from the traditional principles of geriatric medicine. Additionally, it emphasized the diversity of the expertise, and provided new ideas and insights for the clinicians working with older patients anywhere in the world. Also, the 14th EuGMS Congress provided the participants the opportunity to access to the latest experiences in the field of geriatric medicine in the entire world.

The data were compiled from the 14th EuGMS congress booklet and its abstract book. We examined oral and poster presentation distributions by determined topics.

\section{The Community Booth-The Global Europe Initiative}

Since last year, EuGMS has expanded its span to all members of the World Health Organization European Region by including Belarus, Israel, Lithuania, Russia, and Turkey.

Address for Correspondence: Fatma Özge Kayhan Koçak, Ege University Faculty of Medicine, Department of Internal Medicine, Division of Geriatrics, İzmir, Turkey

E-mail: drozgekayhankocak@gmail.com ORCID: orcid.org/0000-0002-6447-2352

Received: Jul 17, 2019 Accepted: Oct 19, 2019

This study was presented at $2^{\text {nd }}$ International and $12^{\text {th }}$ Academic Geriatrics Congress.

Cite this article as: Kayhan Koçak FÖ, Şahin S, Akçiçek SF. Overview of Geriatrics Studies via the 14th EUGMS (European Geriatric Medicine Society) Congress 2018: From Turkey's Point of View. Eur J̉ Geriatr Gerontol 2019;1(3):70-77

๑Copyright 2019 by the Academic Geriatrics Society / European Journal of Geriatrics and Gerontology published by Galenos Publishing House. 
Henceforth, Turkey is a full board member of EuGMS. At this year's congress, a new initiative, called "Community Booth", was launched. This community aimed to share more information about the work of the EuGMS and its national society members, and especially reinforce the relations and collaboration with new members in Eastern and Southern Europe. EuGMS stated that the "Global Europe Initiative" aims to make special efforts to increase the development of geriatrics in countries where it is still in its infancy. Another aim of the society was to be more inclusive of the parts of the topics in geriatric medicine which financial support is especially difficult. Therefore, the society has also provided travel and other grants to participants who make presentations on this topic.

\section{Special Interest Groups}

The group had two scope as "Special Interest Groups" (SIG) and "Task and Finish Groups" (T\&FG). The program of these groups was announced on the official website of EuGMS, for about one week prior to the event. SIG allowed members to share their ideas or networks, exchange views, share best practices with their peers, and develop scientific research on geriatric medicine (Figure 1). T\&FG was designed to examine any service, research, policy or issue that influenced the SIG. SIG could be formed for any subject by at least five members from at least five different member countries. SIG topics of 2018 congress were; 1) Vaccines 2) Cardiovascular medicine 3) Systematic review and meta-analysis 4) Frailty 5) Education \& Training 6) Geriatric rehabilitation 7) Long term care 8) Pharmacology 9) Nutrition 10) Sarcopenia 11) Palliative care. T\&FG titles for year 2018 were "the fall risk increasing drugs" and "gerodontology". All participants can join to these groups, but they should be EuGMS members if they wish to continue attending meetings.

\section{Symposiums}

A total of 70 concurrent symposiums (170 speakers), including eight presentations, were presented. Symposium covered a wide variety of topics in geriatric medicine, such as geriatric approaches in common chronic diseases, new evaluation methods and treatments in geriatric syndromes, long term care (palliative care and intensive care) and the importance of multidisciplinary study. Table 1 depicts whole list of topics. In particular, new developments have been witnessed more closely through sessions of associations such as the European Academy for Medicine of Age (EAMA), the International Association of Gerontology and the Geriatrics for the Europe (IAGG EU). There were three symposium sessions of EAMA; one of them was regarding "research and publication" and the other two were about sarcopenia and comprehensive geriatric assessment. With the fact that the EAMA was directed towards researchers who were at the early stages of their careers, the topics were shed light on the young clinicians' current problems relating to academic life.

\section{The Organizers and Program Committee}

Prof. Md. Jürgen Bauer served as the congress chair and Prof. Md. Anne Ekdahl served as the secretary general. The local committee consisted of 16 people, one of them being the congress chair, from various health care institutions in Germany. Countries with full board membership: Austria, Belarus, Belgium, Czech Republic, Denmark, Estonia, Finland, France, Germany, Greece, Hungary, Iceland, Ireland, Israel, Italy, Latvia, Lithuania, Luxembourg, Malta, Norway, Poland, Portugal, Romania Russia, Serbia, Slovakia, Slovenia, Spain, Sweden, Switzerland, the Netherlands, Turkey and the UK. The observer countries are Albania, Bulgaria, Croatia, and Cyprus. IAGG-ER (International Association of Gerontology and Geriatrics European Region) was represented by Mario Barbagallo, EAMA was represented by Nele Van Den Noortgate, UEMS-GMS (European Union of Medical Specialists Geriatric Medicine Section) was represented by Jaap Krulder.

One hundred and twenty-six oral presentations (Table 2) and 894 poster presentations were made in this congress. The presentations were selected by the program committee according to evaluation of the submitted abstracts. Oral presentations were organized in 14 sessions; 1) Metabolism and nutrition 2) Pre and post-operative care and geriatric rehabilitation 3) Frailty and sarcopenia 4) Longevity and

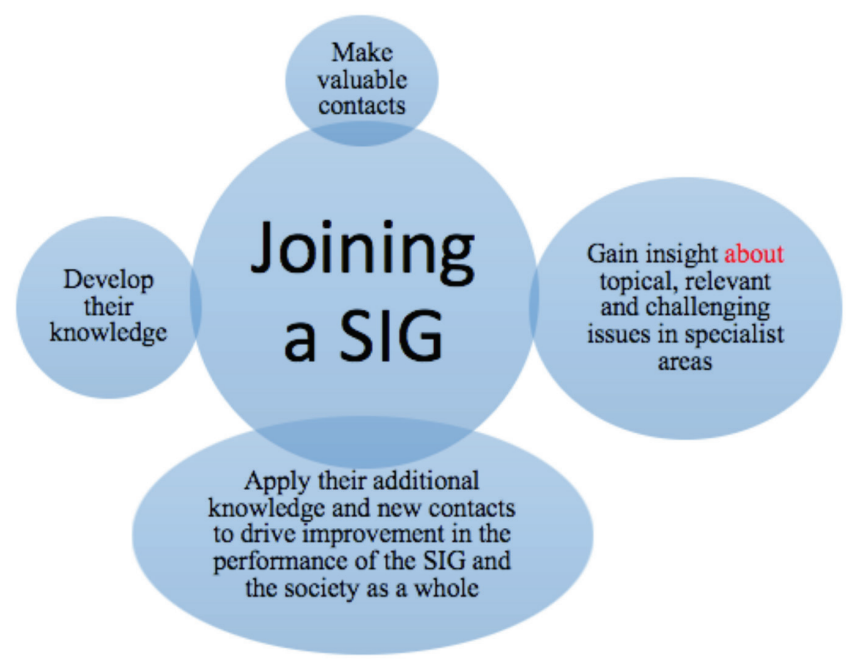

Figure 1. Targeted opportunities of SIG by EuGMS. SIG is interested in topics which are being foreseen as they will gradually become common problems of geriatric medicine. SIG ensures its members valuable contacts by giving them chance to meet the right people, work with people who are active in, and passionate about their field. Organizing seminars, workshops or symposia can help SIG's members to develop their knowledge, and so SIG's members may meet a wide variety of people to gain insight into topical, relevant and challenging issues in specialist areas

SIG: Special Interest Groups, EuGMS: the European Geriatric Medicine Society 


\begin{tabular}{|c|c|}
\hline & Topics \\
\hline \multirow{6}{*}{ SIG-T\&FG } & Diabetes \\
\hline & Palliative care \\
\hline & Gerontodontology \\
\hline & On fall risk increasing drugs \\
\hline & Long-term care \\
\hline & Frailty and resilience \\
\hline \multirow{2}{*}{$\begin{array}{l}\text { EUGMS } \\
\text { symposiums }\end{array}$} & EDA-delirium \\
\hline & IAGG-EU-meaning of ageing \\
\hline \multirow{8}{*}{$\begin{array}{l}\text { Submitted } \\
\text { symposiums }\end{array}$} & Osteosarcopenia \\
\hline & Pharmacology (PIM) \\
\hline & Education \& training \\
\hline & Cognition and dementia (2) \\
\hline & $\begin{array}{l}\text { Geriatrics in organ disease (calcium and vitamin } \\
\text { D supplementation) }\end{array}$ \\
\hline & Cognition and dementia \\
\hline & Geriatric rehabilitation \\
\hline & Gerotechnology \\
\hline \multirow{4}{*}{ Lectures } & Geriatrics in organ disease (osteoporosis) \\
\hline & $\begin{array}{l}\text { Geriatrics in organ disease (syncope } \& \text { transient } \\
\text { loss of consciousness) }\end{array}$ \\
\hline & Pharmacology (polypharmacy) \\
\hline & Frailty and sarcopenia \\
\hline \multirow{2}{*}{$\begin{array}{l}\text { Pros and cons } \\
\text { session }\end{array}$} & Cognition and dementia \\
\hline & Frailty and malnutrition \\
\hline \multirow{9}{*}{$\begin{array}{l}\text { Sponsored } \\
\text { symposiums }\end{array}$} & Metabolism and nutrition \\
\hline & Vaccines and immunization \\
\hline & Frailty and sarcopenia \\
\hline & Frailty and sarcopenia \\
\hline & Urinary incontinence \\
\hline & Vaccines and immunization \\
\hline & Metabolism and nutrition \\
\hline & Frailty and sarcopenia \\
\hline & Vaccines and immunization \\
\hline \multirow{3}{*}{$\begin{array}{l}\text { EAMA } \\
\text { workshops }\end{array}$} & Education \& training \\
\hline & Frailty and sarcopenia \\
\hline & Geriatrics in organ disease \\
\hline \multirow{8}{*}{ Other topics } & $\begin{array}{l}\text { Geriatrics in organ disease (6) (anemia, } \\
\text { cardiovascular disease, hypertension, atrial } \\
\text { fibrillation etc.) }\end{array}$ \\
\hline & Gerotechnology \\
\hline & Cognition and dementia (3) \\
\hline & Oral health in older adults \\
\hline & Frailty and sarcopenia (4) \\
\hline & $\begin{array}{l}\text { Multimorbidity and comprehensive geriatric } \\
\text { assessment (fall, oropharyngeal dysphagia) }\end{array}$ \\
\hline & Metabolism and nutrition \\
\hline & Geriatric rehabilitation (5) \\
\hline
\end{tabular}

\begin{tabular}{|l|l|}
\hline Table 1. Continued \\
\hline \multirow{4}{*}{$\begin{array}{l}\text { Other } \\
\text { topics }\end{array}$} & Topics \\
\cline { 2 - 2 } & Geriatric rehabilitation (5) \\
\cline { 2 - 2 } & Longevity and prevention \\
\cline { 2 - 2 } & Pharmacology (polypharmacy) \\
\cline { 2 - 2 } & Vaccines and immunization (infections) \\
\cline { 2 - 2 } & Acute care (emergency department) \\
\hline $\begin{array}{l}\text { SIG: Special Interest Groups, T\&FG: Task and Finish Groups, EUGMS: The European } \\
\text { Geriatric Medicine Society, EDA: European Delirium Association, IAGG-EU: The } \\
\text { International Association of Gerontology and Geriatrics European, PIM: Potentially } \\
\text { Inappropriate Medications, EAMA: The European Academy for Medicine of Age }\end{array}$ \\
\hline
\end{tabular}

prevention 5) Comorbidity and multimorbidity 6) Geriatric education 7) Organization of care and gerotechnology/urology and continence management/Vaccines and immunization 8) Multimorbidity and comprehensive geriatric assessment 9) Acute care 10) Cognition and dementia 11) Biogerontology and genetics 12) Delirium/Geriatrics in organ disease 13) Ethics and end of life care 14) Pharmacology. Oral presentations were made from 27 different countries' representatives. According to number of oral presentations, the top four countries, also known as The Big Four in advanced global economies of Western Europe, were United Kingdom (UK), Italy, France, and Germany respectively (Table 3 ).

Popular culture is a concept that can be considered as one of the effects of social modernization in the $20^{\text {th }}$ century. The impact of popular culture was seen particularly on metabolism and nutrition topics, such as "eating more fruit and vegetables for happiness" or "fall risk by your body shape". Another noteworthy point was the perspective of successful aging. Kahn and Rowe (1997) defined that successful aging is combination of the avoidance of disease and disability, active engagement in social life and high cognitive, and physical functioning. However, the meaning of successful aging is changed according to multidimensional perceptions of older adults, accepting the aging process, culture, and so objective measures are required instead of subjective measures (1). The most of oral presentations were focused on successful aging based on longevity (aged 90 years and over). The reason could be the change of population distribution by age, by virtue of longer life expectancy. Also, the increasing research on telomeres and aging may be an impact of both the long-life expectancy and popular culture.

All oral presentations on geriatric education topics, except one, were intended only to medical students. On the other hand, studies about staff education were presented on session of ethics and end of life care. Studies supposed that healthcare professionals (except for the doctor) took part only in long-term care. As a result, geriatric training is requirement for all healthcare professionals. When PhD in older patient 
care will become more widespread in all parts of the world, all healthcare professionals' training will be considered important.

Geriatric syndromes are the clinical conditions that are frequently seen in older patients and could cause impairment of quality of life and increased morbidity and mortality. Preexisting comorbidity in older adults is negatively associated with functional rehabilitation outcome after surgical procedures, such as hip fracture (2), and pre-operative comprehensive geriatric assessment is important to reduce the rate of adverse postoperative outcome (3). The majority of the presented surgical researches were about hip fractures. Hip fracture is associated with geriatric syndrome, such as falls, frailty, malnutrition, and it is approached as a new geriatric syndrome.

There was only a presentation about vaccines and immunization, although it's important in the population aged 65 and over. Immunization is an important part of health in older adults, not only in childhood. One of the aims of this congress is to create awareness. I strongly believe that vaccination studies should be more presented in congress.

\section{Table 2. Oral presentations}

\begin{tabular}{l|l|l|l|l|l|l|l|l|l|l|l|l|l|l|l|l|l} 
Continent & Country & P & E & D & B & CD & AC & M & OG & CM & GE & LP & FS & PO & MN & n & \%
\end{tabular}

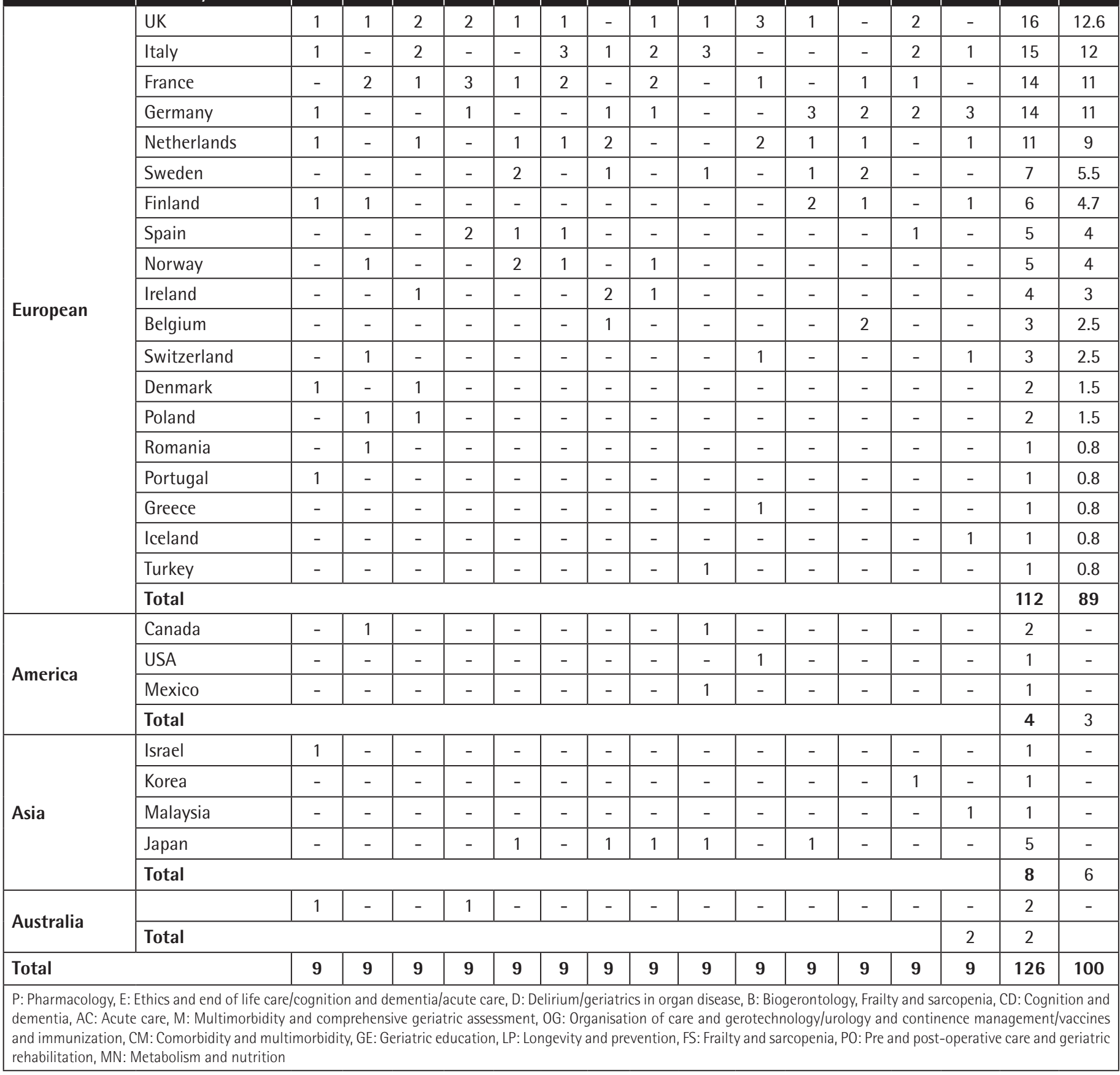




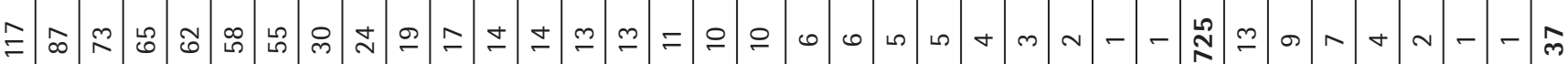

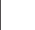
$\sim$ $v--m-$

ш

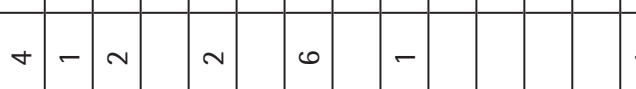

\begin{tabular}{lllllllllll|l|l}
0 & & & & & & & & & & & & \\
\hline
\end{tabular}

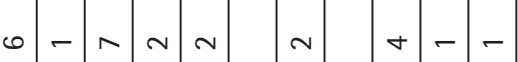

$-$

부으 $\sim-m-$

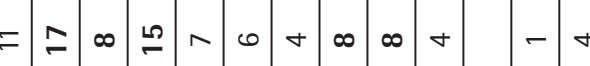




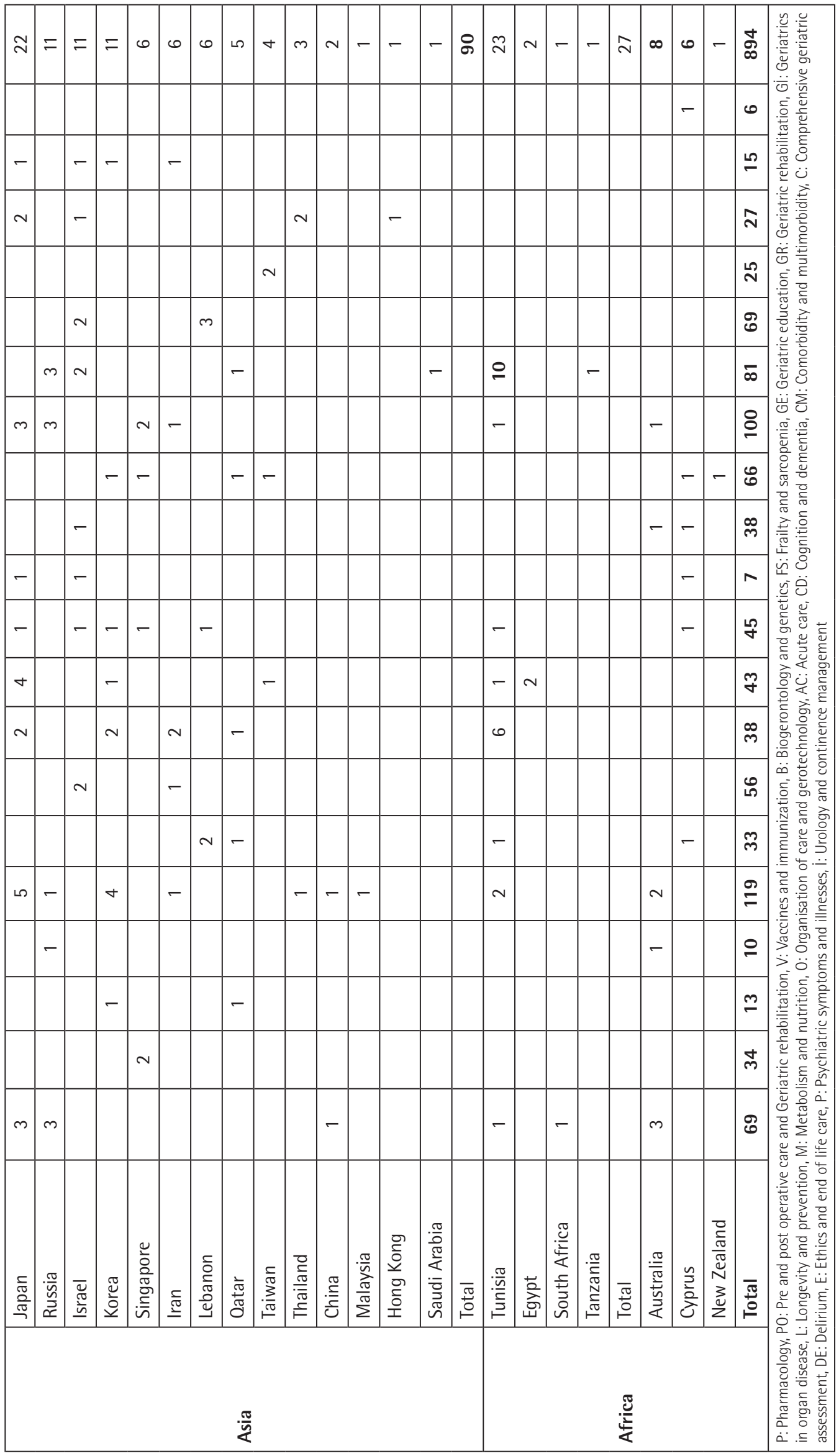

In spite of the intensity of the presentation program, the speakers managed to finish their presentations on time. Attention and awareness of moderators contributed positively to this situation at oral presentations.

The poster presentations were delivered in 20 sessions concerning the following topics; pharmacology, pre and postoperative care, vaccines and immunization, biogerontology and genetics, frailty and sarcopenia, geriatric education, geriatric rehabilitation, geriatrics in organ disease, longevity and prevention, metabolism and nutrition, oral and dental health, organization of care and gerotechnology, acute care, cognition and dementia, comorbidity and multimorbidity, comprehensive geriatric assessment, delirium, ethics and end of life care, psychiatric symptoms and illnesses, urology and continence management. Considering subjects of poster presentations, highest number of posters were related to frailty and sarcopenia (119 posters) and cognition and dementia (100 posters).

Sixty-five poster presentations were sent from Turkey and more than half of them (36 posters) were cross-sectional study. Only four poster presentations were about International Study. Although geriatrics is a multidisciplinary field, a few of studies were made in collaboration with different scientific disciplines. All multidisciplinary studies in Turkey involve collaboration among healthcare professionals only. Gerontology takes part in Faculty of Arts and Sciences in Turkey. It is distinguished from 
geriatrics which is a branch of medicine. Geriatrics should make efforts to be more inclusive in Turkey. Caregivers of the population aged 65 and older are also aging in Turkey, but even then, there is no presentation about the burden of caregivers. So, caregiver burden should be investigated now more than ever.

There are limitations of our article. Firstly, the data were compiled from the congress booklet and abstract book. Therefore, information, such as number of congress participants per country, could not be learned. In addition, poster and oral presentations were classified according to the first author's country, the multicenter studies have not been evaluated in a different table.

\section{Conclusion}

Conferences and sessions on various topics related to the current situation, and future expectations of geriatric medicine were presented in the 14th Congress of the European Geriatrics Association. More than a third of the posters were sent from the European countries. The country with the maximum number of both poster and oral presentations was the UK.

Considering the poster presentations, it was seen that "frailty and sarcopenia" was one of the most popular topics investigated in the Europe. Poster presentations on the topics of frailty and sarcopenia were sent mostly from Spain (17 posters) and Turkey (15 posters). Most of the presented studies in these topics were about the most appropriate criteria for the diagnoses. Sarcopenia and frailty have emerged as crucial problems in the population aged 65 and older, and they represent a rapidly expanding field of research. Sarcopenia frequently overlaps with frailty, and both of them are increasing the risk of negative outcomes, such as disability and mortality. Therefore, they are increasingly viewed as two sides of the same coin (4).

Patients who are at risk for cognitive decline should be identified for developing an appropriate strategy. Intervention and treatment options should be evaluated according to cognitive decline. As a consequence, studies on cognitive function indicated that age-associated chronic diseases and drugs used in treatment were investigated. Also, pharmacology is of interest in other common diseases beside cognitive disorders. Remarkable issues in the field of pharmacology were the use of platelet antiaggregants/anticoagulants, psychiatric medications and anticholinergic burden which is one of frequently overlooked problems, as well as polypharmacy and inappropriate drug use that still maintains its importance.

Orthopedics was the surgical specialty that evaluated the most frequent physical performance while the most popular topic in geriatric education was cognitive function. Overall, it can be said that all presented studies in congress aim to improve the quality of life.
Majority of poster presentations on the topic of the vaccinationimmunization were about varicella-zoster vaccine (six posters) and awareness of health care providers (five posters). When examined poster presentations, we noticed that many countries have started to practice routine varicella vaccination for people 60 years of age or older, by contrast with Turkey.

About one fifth of poster presentations on the topic of the comprehensive geriatric assessment were sent from Turkey, and both polypharmacy/inappropriate drug use and depression seemed to be of equal interest. There was a similar situation in psychiatric symptoms and diseases, Turkey was among the top three countries to send poster presentation on the topic of psychiatric symptoms and diseases, and poster presentations of this topic were sent from only 12 different countries. One of these presentations was about depression and the other two of them were about sleep disorders. There was no poster presentation from Turkey on vaccinationimmunization, biogerontology/genetics, delirium and ethics/ end of life care.

In biogerontology and genetics, telomere, immune aging and microbiota were studied and one third of the poster papers were from France. However, the studies that were sent from Italy and UK were conspicuous. Cherubini showed that Zonulin, a protein synthesized in intestinal and liver cells, can used to evaluate whether a polyphenol rich dietary pattern can modulate intestinal permeability. In addition, study of Scutt was about relation of adverse drug reactions and the nuclear factor erythroid 2-like 2 (Nrf2) gene, a regulatory antioxidant and xenobiotic defense gene, and was presented in both oral abstracts and poster abstracts. These researches have shed light on whether and how genetic predispositions influence with aging.

The least interest of the poster presentations topic was urinary incontinence, and only six poster papers were sent. Similarly, only one of the symposium issues was related to incontinence, and it was sponsored by a personal hygiene brand.

In summary, participants from different disciplines were not only aware of the latest developments in geriatric medicine, also they had the opportunity to exchange views in this area. It is thought that the synergy arising from the congress will contribute to the future applications of the geriatric medicine, while its importance is rapidly increasing all around the world. Moreover, the fact that the congress subjects are similar to the recent studies on geriatrics shows that the EuGMS congress stay up to date. In addition, attendance ratios of the congress from the United States (4\%), Africa (3\%), Australia and island countries (except Malta and UK) (2\%) show that the European congress has an impact on the whole world. As expected, a broader vision of congress has emerged. 


\section{Ethics}

Peer-review: Internally and externally peer-reviewed.

\section{Authorship Contributions}

Surgical and Medical Practices: F.Ö.K.K., S.S.., S.F.A., Concept: F.Ö.K.K., S.Ş., S.F.A., Design: F.Ö.K.K., S.Ş., S.F.A., Data Collection or Processing: F.Ö.K.K., S.Ş., S.F.A., Analysis or Interpretation: F.Ö.K.K., S.Ş., S.F.A., Literature Search: F.Ö.K.K., Writing: F.Ö.K.K.

Conflict of Interest: No conflict of interest was declared by the authors.

Financial Disclosure: The authors declared that this study received no financial support.

\section{References}

1. Martinson $M$, Berridge $C$. Successful aging and its discontents: a systematic review of the social gerontology literature. Gerontologist 2015;55:58-69.

2. Kabboord $A D$, van Eijk $M$, Fiocco $M$, van Balen $R$, Achterberg W P. Assessment of Comorbidity Burden and its Association with Functional Rehabilitation Outcome After Stroke or Hip Fracture: A Systematic Review and MetaAnalysis. J Am Med Dir Assoc 2016;17:1066.e13-1066.e21.

3. Partridge J S L, Harari D, Martin F C, Dhesi J K. The impact of pre-operative comprehensive geriatric assessmenton postoperative outcomes in older patients undergoingscheduled surgery: a systematic review. Anaesthesia 2014;69(Suppl. 1):8-16.

4. Ticinesi A, Nouvenne A, Cerundolo N, Catania P, Prati B, Meschi CT. Gut Microbiota, Muscle Mass and Function in Aging:A Focus on Physical Frailty and Sarcopenia. Nutrients 2019;17:11:1-21. 